\title{
Comparison and evaluation of dietary quality between older and younger Mexican-American women
}

\author{
Giselle AP Pignotti ${ }^{1}$, Sonia Vega-López ${ }^{1,2, *}$, Colleen Keller $^{3}$, Michael Belyea $^{3}$, \\ Barbara Ainsworth ${ }^{1}$, Allison Nagle Williams ${ }^{2,3}$, Kathie Records ${ }^{4}$, Dean Coonrod ${ }^{5}$ \\ and Paska Permana ${ }^{6}$ \\ ${ }^{1}$ Healthy Lifestyles Research Center, School of Nutrition and Health Promotion, Arizona State University, 500 North \\ 3rd Street, Phoenix, AZ 85004, USA: ${ }^{2}$ Southwestern Interdisciplinary Research Center, Arizona State University, \\ Phoenix, AZ, USA: ${ }^{3}$ College of Nursing and Health Innovation, Arizona State University, Phoenix, AZ, USA: \\ ${ }^{4}$ College of Nursing, University of Missouri-St. Louis, St. Louis, MO, USA: ${ }^{5}$ Department of Obstetrics and \\ Gynecology, District Medical Group, Maricopa Integrated Health System, University College of Medicine-Phoenix, \\ Phoenix, AZ, USA: 'Phoenix Veterans Affairs Health Care System, Phoenix, AZ, USA
}

Submitted 14 July 2014: Final revision received 6 November 2014: Accepted 20 November 2014: First published online 7 January 2015

\begin{abstract}
Objective: To compare and evaluate the dietary quality of young and older sedentary Mexican-American women. Understanding key dietary concerns, while considering developmental transition periods and cultural relevance, can provide insight for developing appropriate nutrition interventions.

Design: Cross-sectional dietary data were collected using unannounced $24 \mathrm{~h}$ diet recalls to assess nutrient intake adequacy (Estimated Average Requirement cut-point method) and dietary quality (Healthy Eating Index (HEI) 2010).

Setting: Mujeres en Acción and Madres para la Salud, two community-based physical activity interventions.

Subjects: Participants were 139 young (28 (SD 6) years) and 124 older (55 (SD 7) years) overweight/obese sedentary Mexican-American women $\left(B M I=25 \cdot 0-35 \cdot 0 \mathrm{~kg} / \mathrm{m}^{2}\right)$ of low socio-economic status.

Results: Older women consumed less $\mathrm{Ca}$, Fe, folate, empty calories and energy from carbohydrate, but more fruit, vegetables, greens and beans, and fibre than younger women (all $P<0 \cdot 05$ ). Over $60 \%$ of all participants had an intake below recommendations for fibre, $\mathrm{Ca}$, vitamin $\mathrm{E}$, vitamin $\mathrm{C}$ and folate. Both groups had low total HEI-2010 scores (62 for older and 63 for younger women; NS), with $57 \%$ of older and $48 \%$ of younger women classified as having a poor diet.

Conclusions: Despite differences in nutrient requirements according to developmental transition periods (childbearing $v$. perimenopausal), overall, older and younger Mexican-American women generally had low-quality diets and may benefit from dietary quality improvement.
\end{abstract}

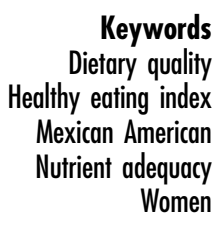

Hispanics in the USA are at disproportionately higher risk for CVD and diabetes, in part due to higher prevalence of obesity and cardiometabolic disease risk factors relative to other ethnic groups ${ }^{(1,2)}$. Poor dietary quality may be a major contributor to these disparities. Available surveillance data on dietary composition suggest that, as for other ethnic groups, the diet of Mexican-American adults is in need of improvement, as indicated by reports of high intakes of solid fats, cholesterol, added sugars and sugarsweetened beverages, and low intakes of vitamins D and $\mathrm{E}$, $\mathrm{Ca}$ and $\mathrm{K}$, whole grains, dairy products, dark greens and highly coloured vegetables ${ }^{(3-7)}$.

Different ethnic subgroups have culture-bound patterns of food purchase, preparation and eating ${ }^{(8)}$, all of which can be affected by environmental resources (e.g. food availability, cost $)^{(9)}$, socio-economic factors (e.g. income, education $)^{(10,11)}$ and other factors known to contribute to unhealthful dietary changes (e.g. acculturation, migration $)^{(12-15)}$. Among women, dietary choices may also be related to age and developmental transition periods ${ }^{(16,17)}$. For example, the challenges of caring for a newborn child while maintaining other responsibilities (e.g. family, work) are potential barriers for following healthful dietary practices among postpartum women. Among older women, life and emotional stresses that accompany ageing may also compromise healthful eating ${ }^{(18)}$. Potential differences in dietary quality among Hispanic women of different life stages have not been reported. An understanding of the 
key dietary concerns for this subgroup at different stages of life can provide insight for developing appropriate nutrition interventions characterized by developmental transitions and cultural relevance.

The purpose of the present report is to evaluate the baseline dietary quality of overweight/obese young and older Mexican-American women, most of them living under disadvantaged socio-economic conditions, enrolled in two culturally relevant, community-based, social-support interventions designed to increase daily walking for weight loss conducted in the greater Phoenix, AZ, area, USA. Physical activity (PA) data and intervention outcomes have been reported elsewhere ${ }^{(19-21)}$. This report of dietary intake among two groups of Mexican-American women is important for two reasons. First, an understanding of dietary quality in Mexican-American women during two distinctive life transition periods (childbirth and perimenopause) can suggest a research-application paradigm that can be successfully used to promote healthy development not only over a lifetime but across generations ${ }^{(22)}$. This perspective suggests that numerous factors converge at passage points such as childbearing (as fat storage and fertility are linked in human females ${ }^{(23)}$ ) and menopause (related to a relatively sedentary lifestyle in modern populations), which contribute to weight accumulation in women $^{(18)}$. Second, a Mexican-American woman's values are, in the case of many Hispanic women, still built on core traditional values that are deeply embedded in her dietary practices and play a role in guiding activities of daily living, including food preparation and intake ${ }^{(24)}$. Modernization, migration and experience living in a historically and predominantly non-Hispanic culture may have transformed the traditional culture of Hispanics. While change does occur, traditions continue to shape Mexican-American women's behaviour, which is influenced by deeply held, and less likely to change, traditional values including food intake ${ }^{(25)}$.

\section{Experimental methods}

\section{Participants}

Participants were Mexican-American women enrolled into Mujeres en Acción (Women in Action; hereafter, 'Mujeres'; older; $n$ 124; $45-70$ years) ${ }^{(19)}$ and Madres para la Salud (Mothers for Health; hereafter, 'Madres'; younger; $n$ 139; 18-40 years; at least 6 weeks but less than 6 months after childbirth) ${ }^{(20)}$. Both studies recruited participants through community organizations (e.g. churches, community centres, agencies) that serve Hispanic residents in the greater Phoenix, AZ, area, USA, resulting in the enrolment of a large number of women living under disadvantaged socioeconomic conditions. Mujeres was conducted from 2008 to 2010; Madres was conducted from 2009 to 2012.

Participants of both programmes were habitually sedentary women, but physically able to participate in moderate-intensity PA in the form of walking. Habitual sedentary activity was assessed by self-report of $<150 \mathrm{~min}$ of moderate $\mathrm{PA} / \mathrm{d}$ in Mujeres participants, and by the Stanford Brief Activity Survey (SBAS, a brief self-report screening tool and categorical measure of PA status) in Madres participants ${ }^{(26,27)}$. The SBAS uses reports of occupational and leisure-time PA to classify respondents' overall PA intensity levels on a 5-point scale. Exclusion criteria included: currently engaged in regular, strenuous PA; currently pregnant or planning on becoming pregnant within the next 12 months; using antidepressants or antiinflammatory medications; and having a BMI of $<25.0 \mathrm{~kg} / \mathrm{m}^{2}$ or $>35.0 \mathrm{~kg} / \mathrm{m}^{2}$. While parity is a documented risk for postpartum weight retention, the younger women were not excluded for parity; this was the first pregnancy for twentyeight women $(20 \cdot 1 \%)$ with the remainder ( $n$ 111, 79.9\%) reporting two to six births. Both studies were approved by Arizona State University's Institutional Review Board and all participants gave written consent to participate.

\section{Measures}

All data were collected by trained research staff prior to the randomization allocation. Height, weight and waist circumference were measured in triplicate following standard procedures. A questionnaire captured information on age, annual household income (0-\$US 20000 or $>\$$ US 20000 ) and birthplace (USA, Mexico or other). Acculturation was determined using Hazuda acculturation scales ${ }^{(28)}$, that includes information on language use and proficiency, cultural beliefs and family values. Each dimension of the scale ranges from 1, indicating lowest acculturation, to 4 , indicating highest acculturation.

\section{Diet assessment}

Baseline dietary intake data were obtained using one (in Mujeres) or three (in Madres) unannounced $24 \mathrm{~h}$ recalls at baseline using a five-step, multiple-pass method ${ }^{(29)}$. All diet data were collected and entered by trained bilingual staff. The dietary recalls were collected during all seven days of the week. Dietary data were analysed using Nutrition Data System for Research (NDSR) software version 2009, developed by the Nutrition Coordinating Center (NCC), University of Minnesota, Minneapolis, MN, USA. Dietary variables of interest were estimates of total energy intake, amount and percentage of energy provided by macronutrients, and selected micronutrients relevant to women's health ( $\mathrm{Ca}, \mathrm{Fe}$, folate and vitamins $\mathrm{C}$ and $\mathrm{E}$ ).

Intake adequacy of selected nutrients was evaluated by estimating the proportion of participants meeting current Dietary Reference Intake (DRI) recommendations following the Estimated Average Requirement (EAR) cut-point method, as recommended by the Institute of Medicine to evaluate the nutrient intake of groups ${ }^{(30)}$. This method uses the EAR specific for gender and age as the recommended intake standard; when an EAR is not available (e.g. for dietary fibre), the Adequate Intake is used ${ }^{(30)}$. 
While assessing the adequacy of specific nutrients in a diet is important, evaluating the diet as a whole captures the complexity of nutrient interactions and the presence of bioactive components ${ }^{(31)}$. A current approach to evaluating overall dietary quality is the Healthy Eating Index (HEI), an algorithm that measures conformance to the Dietary Guidelines for Americans ${ }^{(32)}$ and was recently modified to be consistent with the dietary recommendations released in 2010 (HEI-2010) ${ }^{(33)}$.

Diet quality was assessed by calculating the HEI-2010, as described previously ${ }^{(33)}$. Briefly, the HEI-2010 includes twelve components divided into food groups or nutrients that capture dietary adequacy (i.e. food groups or nutrients that should be included in the diet: total fruit, whole fruit, total vegetables, greens and beans, whole grains, dairy, total protein foods, seafood and plant proteins, and fatty acids) and ones that capture moderation (i.e. food groups or nutrients that should be limited: refined grains, sodium and empty calories). Individual components are scored from 0 to 5,10 or 20, depending on the food or nutrient category; the maximum total score is 100. For adequacy components, the maximum score corresponds to intake equal to or greater than the level of the recommended intake. For moderation components, the maximum score is assigned for intake at or below the maximum recommended level of intake, reflecting lower consumption. The scoring standards are assessed on a density basis, focusing on diet quality instead of quantity, with each individual component assessed as amount per intake of $4184 \mathrm{~kJ}(1000 \mathrm{kcal})$, percentage of total energy intake or a ratio ${ }^{(33)}$. The score of the population ratio (the studied group's total intake of each individual component divided by the group's total energy intake) was used to reduce the bias in estimating usual intakes of the two groups assessed (Madres and Mujeres). The total HEI-2010 score is calculated as the sum of all individual components ${ }^{(34)}$. The conventional cut-off points for the HEI are as follows: total HEI $>80$ is indicative of a 'good' diet; scores between 51 and 80 indicate a need for improvement; and scores $<51$ are indicative of a poor diet ${ }^{(35)}$. The individual components are also expressed as the percentage of the maximum score, with a higher score indicating intake at a level closer to recommendations (i.e. greater intake for adequacy and lower intake for moderation components). The recommended approach to calculating HEI scores using NDSR was followed ${ }^{(36)}$.

\section{Statistical analysis}

All statistical analyses were conducted with the statistical software package IBM SPSS Statistics for Windows, version 21.0. Descriptive characteristics of participants and dietary data are presented in text and tables as means and standard deviations for continuous variables and as percentages of the total sample for categorical variables. Nutrient intake for carbohydrate, protein, fat and saturated fat was expressed as a percentage of total energy. Data were initially tested for homogeneity of variance using the Levene test. Independent-samples $t$ tests were then used to perform between-group comparisons of general descriptive characteristics, sugars intake and diet quality scores. A $\chi^{2}$ analysis was used to compare categorical variables of descriptive characteristics. Nutrient intakes between younger and older women were compared using a multivariate ANCOVA, adjusting for age, BMI, body fat percentage, income and birthplace. Statistical significance was set at $P<0 \cdot 05$. HEI-2010 scores were expressed as an absolute score and percentage of the maximum score. Of 126 Mujeres participants, two did not provide diet data and were excluded from the present analysis. Acculturation data were available only for ninety-four Mujeres and eighty-one Madres participants.

\section{Results}

\section{Participant characteristics}

The sample comprised 124 older (Mujeres, 55 (SD 7) years old) and 139 younger (Madres, 26 (SD 8) years old) women who had complete dietary data (Table 1). Mean BMI values were in the obese and overweight range for older and younger women, respectively $(P<0.001)$. Almost two-thirds reported an annual household income below \$US 20000 (59\% of older and $71 \%$ of younger women, $P=0.049)$. Fifty per cent of the older participants were born in the USA, while most (78\%) of the younger participants were born in Mexico $(P<0 \cdot 001)$. According to Hazuda acculturation scales ${ }^{(28)}$, older women were more acculturated regarding childhood language experience $(P<0.001)$ and adult language usage $(P<0.001)$. However, there were no differences related to value placed on Mexican cultural origin and attitude towards traditional family structure and sex role organization, and adult proficiency in English.

\section{Dietary intake}

A summary of dietary intake data and DRI recommendations for the older and younger women is provided in Table 2. Reported mean total energy intake was $5883 \mathrm{~kJ}$ $(1406 \mathrm{kcal})$ and $6176 \mathrm{~kJ}(1476 \mathrm{kcal})$ daily for older and younger women, respectively, with no significant difference between groups. The percentage of energy from carbohydrate and the intakes of $\mathrm{Ca}, \mathrm{Fe}$ and folate were significantly lower in the older than in the younger women (all $P<0 \cdot 01$ ). In contrast, dietary fibre intake was significantly higher in the older women than among the younger women $(P=0.020)$. A listing of lead food sources of selected nutrients is displayed in the online supplementary material, Supplemental Table 1.

Table 3 indicates the amount of added sugars provided by sugar-sweetened beverages. Older women consumed significantly less added sugars than younger women $(P<0.0001)$. Of all added sugars consumed, the proportion 
Table 1 Characteristics of study participants*: overweight/obese sedentary Mexican-American women of low socio-economic status enrolled in two community-based physical activity interventions in the greater Phoenix, AZ, area, USA

\begin{tabular}{|c|c|c|c|c|c|}
\hline \multirow[b]{2}{*}{ Characteristic } & \multicolumn{2}{|c|}{ Mujeres (older, $n$ 124) } & \multicolumn{2}{|c|}{ Madres (younger, $n$ 139) } & \multirow[b]{2}{*}{$P$ value } \\
\hline & Mean & SD & Mean & SD & \\
\hline Age (years) & $55 \cdot 0$ & $7 \cdot 0$ & $28 \cdot 0$ & $6 \cdot 0$ & 0.000 \\
\hline BMI $\left(\mathrm{kg} / \mathrm{m}^{2}\right)$ & $32 \cdot 9$ & $7 \cdot 5$ & $29 \cdot 6$ & 3.5 & 0.000 \\
\hline Waist-to-hip ratio & 0.9 & $0 \cdot 1$ & $0 \cdot 8$ & 0.1 & 0.185 \\
\hline Body fat $(\%)$ & $40 \cdot 9$ & $6 \cdot 9$ & 38.6 & 4.6 & 0.002 \\
\hline \multicolumn{6}{|l|}{ Acculturation measures $\dagger$} \\
\hline Childhood language experience & 1.8 & $1 \cdot 2$ & $1 \cdot 1$ & 0.5 & 0.000 \\
\hline Adult proficiency in English & $2 \cdot 8$ & $1 \cdot 8$ & 2.5 & 1.0 & 0.070 \\
\hline Adult language usage & $2 \cdot 4$ & $1 \cdot 1$ & 1.7 & 0.9 & 0.000 \\
\hline Cultural values & 1.7 & 0.9 & 1.6 & 0.8 & 0.325 \\
\hline Family attitude & $2 \cdot 1$ & 0.9 & $2 \cdot 2$ & 0.9 & 0.311 \\
\hline \multicolumn{6}{|l|}{ Annual total household income (\%) } \\
\hline 0-\$US 20000 & \multicolumn{2}{|c|}{59} & \multicolumn{2}{|c|}{71} & 0.049 \\
\hline >\$US 20000 & \multicolumn{2}{|c|}{41} & \multicolumn{2}{|c|}{29} & \\
\hline \multicolumn{6}{|l|}{ Birthplace (\%) } \\
\hline USA & \multicolumn{2}{|c|}{50} & \multicolumn{2}{|c|}{15} & 0.000 \\
\hline Mexico & \multicolumn{2}{|c|}{47} & \multicolumn{2}{|c|}{78} & \\
\hline Other & \multicolumn{2}{|c|}{3} & \multicolumn{2}{|c|}{7} & \\
\hline
\end{tabular}

Mujeres, Mujeres en Acción (Women in Action; participants aged 45-70 years, conducted from 2008 to 2010); Madres, Madres para la Salud (Mothers for Health; participants aged 18-40 years, conducted from 2009 to 2012).

*Data for annual household income and birthplace are shown as percentage of participants within each category.

†For Hazuda scales, $1=$ lowest and $4=$ highest acculturation; $n 94$ for Mujeres and $n 81$ for Madres.

Table 2 Comparison of daily intakes of total energy, macronutrients and selected micronutrients between age groups relative to DRI values*: overweight/obese sedentary Mexican-American women of low socio-economic status enrolled in two community-based physical activity interventions in the greater Phoenix, AZ, area, USA

\begin{tabular}{|c|c|c|c|c|c|c|c|c|}
\hline \multirow[b]{2}{*}{ Characteristic } & \multicolumn{3}{|c|}{ Recommended intakes } & \multicolumn{2}{|c|}{ Mujeres (older, $n$ 124) } & \multicolumn{2}{|c|}{ Madres (younger, $n$ 139) } & \multirow[b]{2}{*}{$P$ value } \\
\hline & DRI & $\begin{array}{c}\text { Women } \\
51-70 \text { years }\end{array}$ & $\begin{array}{c}\text { Women } \\
19-30 \text { years }\end{array}$ & Mean & SD & Mean & SD & \\
\hline Energy (kJ) & & & & $5882 \cdot 7$ & $1962 \cdot 3$ & $6175 \cdot 6$ & $2221 \cdot 7$ & $0 \cdot 182$ \\
\hline Energy (kcal) & & & & $1406 \cdot 0$ & $469 \cdot 0$ & $1476 \cdot 0$ & $531 \cdot 0$ & 0.182 \\
\hline Fat (\% of energy) & AMDR & $20-35$ & $20-35$ & $32 \cdot 8$ & $10 \cdot 1$ & $30 \cdot 8$ & 6.6 & 0.123 \\
\hline Saturated fat (\% of energy) & & & & 11.4 & 4.0 & $10 \cdot 4$ & $2 \cdot 7$ & 0.461 \\
\hline Protein (\% of energy) & AMDR & $10-35$ & $10-35$ & $17 \cdot 3$ & 5.4 & $16 \cdot 1$ & $4 \cdot 1$ & 0.268 \\
\hline Carbohydrate (\% of energy) & AMDR & $45-65$ & $45-65$ & $49 \cdot 2$ & $12 \cdot 5$ & $53 \cdot 4$ & $8 \cdot 2$ & 0.004 \\
\hline Total sugars $(\mathrm{g})$ & & & & $74 \cdot 7$ & $44 \cdot 8$ & 94.9 & 44.9 & 0.103 \\
\hline Total dietary fibre (g) & Al & 21 & 25 & $15 \cdot 2$ & 7.5 & 13.5 & $7 \cdot 1$ & 0.020 \\
\hline $\mathrm{Na}(\mathrm{mg})$ & UL & 2300 & 2300 & $2554 \cdot 0$ & $1119 \cdot 0$ & $2606 \cdot 0$ & $1122 \cdot 0$ & 0.139 \\
\hline $\mathrm{Ca}(\mathrm{mg})$ & EAR & 1000 & 800 & $661 \cdot 0$ & 394.0 & $779 \cdot 0$ & 353.0 & 0.004 \\
\hline $\mathrm{Fe}(\mathrm{mg})$ & EAR & 5 & 8 & 11.8 & 6.9 & $12 \cdot 4$ & 6.8 & 0.006 \\
\hline Total folate $(\mu \mathrm{g})$ & EAR & 320 & 320 & 311.0 & $207 \cdot 0$ & 325.0 & 203.0 & 0.003 \\
\hline Vitamin C (mg) & EAR & 60 & 60 & $68 \cdot 3$ & 61.9 & 61.4 & $52 \cdot 3$ & 0.894 \\
\hline Vitamin E (mg) & EAR & 12 & 12 & 4.9 & 3.5 & 4.8 & 2.9 & 0.838 \\
\hline
\end{tabular}

DRI, Dietary Reference Intake; Mujeres, Mujeres en Acción (Women in Action; participants aged 45-70 years, conducted from 2008 to 2010); Madres, Madres para la Salud (Mothers for Health; participants aged 18-40 years, conducted from 2009 to 2012); AMDR, Acceptable Macronutrient Distribution Range; Al, Adequate Intake; UL, Upper Limit; EAR, Estimated Average Requirement.

*Mean values for nutrient intake between older and younger women were compared using ANCOVA, adjusted for age, BMI, body fat percentage, place of birth and income. Data shown are unadjusted means.

contributed by sugar-sweetened beverages was significantly lower among the older women than in the younger women $(P<0 \cdot 0001)$.

The majority of participants (83\% of the older and $93 \%$ of the younger women) had an intake below the DRI for dietary fibre ${ }^{(37)}$. When comparing intake with current $\mathrm{Ca}$ DRI values ${ }^{(38)}, 84 \%$ of the older and $59 \%$ of the younger women had an intake below recommendations. Fe intake was below recommendations ${ }^{(39)}$ for $14 \%$ of the older and
$29 \%$ of the younger women. For folate, $71 \%$ of the older and $65 \%$ of the younger women did not reach the recommended intake ${ }^{(40)}$. Inadequate intake of vitamin $\mathrm{C}^{(41)}$ was observed in $60 \%$ of the older and $63 \%$ of the younger women. Similarly, vitamin E intake was below that recommended ${ }^{(41)}$ for most participants (96\% of older, $98 \%$ of younger women). For $\mathrm{Na}, 45 \%$ of the older and $56 \%$ of the younger women had an intake above the recommended $2300 \mathrm{mg} / \mathrm{d}^{(32)}$. 
Table 3 Comparison of sugars intake and sugars from SSB between age groups*, $\dagger$ : overweight/obese sedentary Mexican-American women of low socio-economic status enrolled in two community-based physical activity interventions in the greater Phoenix, AZ, area, USA

\begin{tabular}{|c|c|c|c|c|c|}
\hline \multirow[b]{2}{*}{ Characteristic } & \multicolumn{2}{|c|}{ Mujeres (older, $n$ 124) } & \multicolumn{2}{|c|}{ Madres (younger, $n$ 139) } & \multirow[b]{2}{*}{$P$ value } \\
\hline & Mean & SD & Mean & SD & \\
\hline Added sugars (g) & $42 \cdot 4$ & 38.8 & $62 \cdot 8$ & 35.4 & $<0.0001$ \\
\hline Added sugars from SSB (g) & $20 \cdot 6$ & 34.7 & $32 \cdot 8$ & $26 \cdot 6$ & 0.002 \\
\hline Added sugars from SSB $(\%) \dagger$ & 28.3 & $36 \cdot 8$ & 43.6 & $26 \cdot 2$ & $<0.0001$ \\
\hline Energy from SSB ( $\%$ of total energy) & $5 \cdot 6$ & $9 \cdot 4$ & $9 \cdot 4$ & $7 \cdot 1$ & $<0.0001$ \\
\hline
\end{tabular}

SSB, sugar-sweetened beverages; Mujeres, Mujeres en Acción (Women in Action; participants aged 45-70 years, conducted from 2008 to 2010); Madres, Madres para la Salud (Mothers for Health; participants aged 18-40 years, conducted from 2009 to 2012).

*Mean values for sugars intake between older and younger women were compared using a $t$ test.

†Five Mujeres participants reported consuming no added sugars and were excluded from this comparison.

Table 4 Comparison of estimated mean total HEI-2010 and component scores, expressed as absolute score and percentage of the maximum score, between age groups*: overweight/obese sedentary Mexican-American women of low socio-economic status enrolled in two community-based physical activity interventions in the greater Phoenix, AZ, area, USA

\begin{tabular}{|c|c|c|c|c|c|c|c|}
\hline \multirow[b]{3}{*}{ Component (score range) } & \multicolumn{3}{|c|}{ Mujeres (older, $n$ 124) } & \multicolumn{3}{|c|}{ Madres (younger, $n$ 139) } & \multirow[b]{3}{*}{$P$ value } \\
\hline & \multicolumn{2}{|c|}{ Absolute score } & \multirow[b]{2}{*}{$\%$ of max. score } & \multicolumn{2}{|c|}{ Absolute score } & \multirow[b]{2}{*}{$\%$ of max. score } & \\
\hline & Mean & SD & & Mean & SD & & \\
\hline \multicolumn{8}{|l|}{ Adequacy components } \\
\hline Total fruit $(0-5)$ & 3.5 & 0.5 & 70 & $2 \cdot 6$ & 0.2 & 52 & 0.105 \\
\hline Whole fruit $(0-5)$ & $5 \cdot 0$ & 0.8 & 100 & $3 \cdot 3$ & 0.3 & 66 & 0.042 \\
\hline Total vegetables $(0-5)$ & $3 \cdot 7$ & 0.3 & 74 & $2 \cdot 6$ & 0.1 & 52 & 0.001 \\
\hline Greens and beans $(0-5)$ & 4.8 & 0.8 & 96 & $2 \cdot 9$ & 0.4 & 58 & 0.024 \\
\hline Whole grains $(0-10)$ & $6 \cdot 7$ & 0.7 & 67 & $10 \cdot 0$ & 0.3 & 100 & 0.000 \\
\hline Dairy $(0-10)$ & $5 \cdot 4$ & 0.5 & 54 & $6 \cdot 4$ & 0.4 & 64 & 0.085 \\
\hline Total protein foods $(0-5)$ & $5 \cdot 0$ & 0.0 & 100 & $5 \cdot 0$ & 0.0 & 100 & 1.000 \\
\hline Seafood and plant proteins $(0-5)$ & $4 \cdot 1$ & 0.6 & 82 & 4.7 & 0.6 & 94 & 0.432 \\
\hline Fatty acids $(0-10)$ & 3.4 & 0.5 & 34 & $4 \cdot 1$ & 0.3 & 41 & 0.179 \\
\hline \multicolumn{8}{|l|}{ Moderation components } \\
\hline Refined grains $(0-10)$ & $7 \cdot 8$ & 0.5 & 78 & $8 \cdot 2$ & 0.4 & 82 & 0.465 \\
\hline Sodium $(0-10)$ & $2 \cdot 1$ & 0.7 & 21 & $2 \cdot 8$ & 0.5 & 28 & 0.436 \\
\hline Empty calories (0-20) & $11 \cdot 1$ & 0.5 & 56 & $9 \cdot 4$ & 0.4 & 47 & 0.012 \\
\hline Total score $(0-100)$ & $62 \cdot 0$ & 1.4 & 62 & 62.5 & 1.4 & 63 & 0.790 \\
\hline
\end{tabular}

HEI-2010, Healthy Eating Index-2010; Mujeres, Mujeres en Acción (Women in Action; participants aged 45-70 years, conducted from 2008 to 2010); Madres, Madres para la Salud (Mothers for Health; participants aged 18-40 years, conducted from 2009 to 2012).

${ }^{*}$ Mean values for total HEI-2010 and component scores between older and younger women were compared using a $t$ test.

\section{Healtby Eating Index-2010}

Mean HEI-2010 individual and total scores and the percentage of the maximum possible score for each component are presented in Table 4. For the adequacy component scores, whole fruit, total vegetables, and greens and beans were significantly higher among the older than among the younger women (all $P<0.05$ ). In contrast, the whole grains score was significantly lower among the older than among the younger women $(P=0 \cdot 000)$. For moderation components, younger women had a significantly lower score for empty calories than older women $(P=0 \cdot 012)$, which suggests higher intake of empty calories. Nevertheless, the score for both groups was indicative of high consumption of foods with low nutrient density.

Most individual component scores were below the maximum attainable score: dairy (54\% and 64\%), fatty acids (34\% and $41 \%$ ), sodium (21\% and $28 \%$ ), and empty calories ( $56 \%$ and $47 \%$ ) in the older and younger women, respectively; total fruit (52\%), whole fruit (66\%), total vegetables ( $52 \%$ ), and greens and beans (58\%) in younger women; and whole grains (67\%) in older women. Both groups reached the maximum possible score for total protein. Maximum possible scores were observed for whole fruits in the older women and for whole grains in the younger women.

The total composite HEI-2010 score did not differ significantly between groups (62 (SD 1) for older and 63 (SD 1) for younger women). Based on the total HEI-2010 score, $57 \%$ of the older and $48 \%$ of the younger women were classified as having a poor diet (total HEI-2010<51). Moreover, the diet of $42 \%$ of the older and $52 \%$ of the younger women was classified as needing improvement (total HEI-2010 $=51-80$ ). Only $1 \%$ of older women were classified as having a good diet (total HEI-2010>80).

\section{Discussion}

The present study compared the diet quality by evaluating nutrient intakes and the HEI-2010 scores of older and 
younger sedentary Mexican-American women who were enrolled in two social-support PA interventions conducted in the Phoenix, AZ, metropolitan area, USA. Both interventions included a large proportion of women living under disadvantaged socio-economic conditions. The interventions reported herein targeted women at two critical developmental transition times: the childbearing and midlife years (Madres and Mujeres, respectively). The comparison of women in these two life stages provides important information regarding potential health risks derived from poor dietary quality and inadequate nutrient intake during developmental transitions at which life stressors and limited time availability may negatively influence health behaviours ${ }^{(42-44)}$.

Findings indicated that a large proportion of both the older and younger women had an inadequate intake of various nutrients, including fibre, $\mathrm{Ca}$, folate, vitamin $\mathrm{C}$ and vitamin E. This was also reflected by both groups having low scores for some individual components and a low total HEI-2010 score. Poor conformance to dietary guidelines in the present study may not be solely related to age and cultural background but also to participants' low socio-economic status. Nearly $60 \%$ of participating women had an annual income <\$US 20 000. It has been documented that income, education and acculturation are inversely related to dietary quality ${ }^{(12,15,45-47)}$. The sociodemographic environment of the geographic area from which study participants were recruited may have contributed to its residents' access to traditional or familiar foods and their ability to meet current dietary recommendations. Moreover, participants were recruited from areas known to have food deserts (urban areas in which at least $20 \%$ of residents live in poverty and at least $33 \%$ live more than $1.6 \mathrm{~km}$ (1 mile) away from a grocery store $)^{(48)}$.

Relative to older women, younger women had significantly lower HEI-2010 scores for whole fruit, total vegetables, greens and beans, and empty calories. At the same time, younger women had a higher HEI-2010 score for whole grains than older women. These findings confirm previous evidence from surveillance data of dissimilarities in dietary quality of women at different stages of life, regardless of equivalent cultural background ${ }^{(16,17)}$. The evaluation of diet quality, using HEI-2005, in the National Health and Nutrition Examination Survey (NHANES) 2002-2003 data revealed higher scores in seven out of twelve components in older (55-64 years) compared with younger adults (18-30 years ${ }^{(17)}$. In addition, a review of six cohort and ten national cross-sectional studies showed that energy and food quantity intake decreased but nutrient density improved with age, despite absolute nutrient intake values often being below the $\mathrm{RDA}^{(16)}$.

\section{Micronutrient and fibre intakes}

Inadequate micronutrient intake, a potential result of low dietary quality, is a public health concern among women at different stages of life due to its consequences on pregnancy outcomes among childbearing women and maintenance of bone health and neurological functions among perimenopausal women ${ }^{(42)}$. A large proportion of participants in both studies were at risk for intake inadequacy for the majority of micronutrients analysed. The current study did not include supplementation use in the nutrient analyses, as the main interest was to evaluate diet quality. There is a possibility that some women classified as not meeting certain recommendations may be obtaining assessed nutrients from supplements. Thus, results on dietary inadequacy and conformance to the dietary guidelines should be interpreted with caution. Intake inadequacy was observed for over $80 \%$ of participants in both groups for dietary fibre and vitamin E, and for over $60 \%$ of participants for vitamin $\mathrm{C}$ and folate. This finding is consistent with national representative data that have shown vitamins $\mathrm{A}, \mathrm{C}$ and $\mathrm{E}$, and total fibre to be at greatest risk for inadequacy across all life stages ${ }^{(49,50)}$. Inadequate intakes of vitamins $\mathrm{C}$ and $\mathrm{E}$ observed in our study and by others may reflect a diet with low amount or poor variety of fruits and vegetables ${ }^{(7,51)}$. This is of importance because antioxidants commonly found in fruits and vegetables (vitamins A, C, and E, carotenoids and polyphenols) have been associated with lower chronic disease risk ${ }^{(52-55)}$.

The average total fibre intake observed in the present study $(15.2(\mathrm{SD} 7.5) \mathrm{g} / \mathrm{d}$ for the older women and 13.5 (SD 7.1) $\mathrm{g} / \mathrm{d}$ for the younger women) was far below current recommendations but consistent with previously reported data among older Mexican-American women $(17 \mathrm{~g} / \mathrm{d})^{(56)}$ and US women over 18 years of age $(13-15 \mathrm{~g} / \mathrm{d})^{(50)}$. Higher intake of fibre is associated with reduced CVD risk and is recognized to decrease cholesterol, blunt glycaemic response and increase satiety ${ }^{(57,58)}$.

Mexican-American women have been reported to be at higher risk of osteoporosis and low bone mass than non-Hispanic White and Black women ${ }^{(59)}$, making Ca a nutrient of interest for this subgroup of the population. In the present study, $84 \%$ of the older and $59 \%$ of the younger women had an inadequate $\mathrm{Ca}$ intake. In other observations, up to $98 \%$ of older Mexican-American women over 50 years of age did not meet the recommended intake of $\mathrm{Ca}^{(56)}$.

Folate intake is of particular concern to childbearing Hispanic women, considering that neural tube defects are more prevalent in Hispanic women ${ }^{(60)}$, as is an increasing parity rate ${ }^{(61)}$. The current study showed that $71 \%$ of the older and $65 \%$ of the younger participants had an inadequate folate intake. Results from a previous study also suggested a high prevalence of inadequate folate intake among Mexican-American women (80-90\% of women aged 25-64 years), especially among those with higher acculturation levels ${ }^{(62)}$, potentially due to differences in food choices and exposure to folate-containing vegetables. 
Healthy Eating Index-2010 and dietary quality

In the present study, both groups of women had low mean total HEI-2010 scores (62 (SD 1) for the older women and 63 (SD 1) for the younger women, relative to a maximum score of 100). Considerable improvements in dietary quality are needed in both groups of women, as nearly all of the women had a total HEI-2010 score lower than $80^{(35)}$. Nevertheless, a recent report using dietary data from a nationally representative sample (NHANES 2001-2002 and 2007-2008) suggested that at the population-level HEI-2010 total score (53) was lower than those observed in the current study ${ }^{(63)}$. While women from the present study had better individual scores for greens and beans, whole grains, seafood and plant proteins, and refined grains than those reported for the general population, their scores were worse for sodium intake.

\section{Adequacy components of the Healtby Eating Index-2010}

The older women in our study had higher scores for all fruit and vegetable components than the younger women. It has been suggested that with increasing age, women become more health conscious and willing to follow a better diet to prevent or manage chronic diseases ${ }^{(17)}$. In contrast, the older women in the present study had lower scores for whole grains than the younger women. This was unexpected because previous NHANES 2003-2004 data indicated higher whole grains scores with increasing age $^{(17)}$. Moreover, whole grains scores observed in our study $(67 \%$ of maximum score in the older and $100 \%$ of maximum score in the younger women) are higher than those previously reported using nationally representative data $(13 \%$ of maximum score for younger adults and $34 \%$ of maximum score in older adults using NHANES 2003-2004 data) ${ }^{(17,63)}$. While error associated with dietary data cannot be ruled out, two additional factors could partly contribute to an overestimation of whole grains scores in the current study: (i) whereas HEI assessment from NHANES data has been generally performed using the MyPyramid Equivalents Database ${ }^{(64)}$, data from the current study were analysed using NDSR. The latter system has been reported to overestimate whole grains intake, which concomitantly may result in underestimation of refined grains than when using the MyPyramid Equivalents Database ${ }^{(36)}$; (ii) the present study included Mexican-American women only. In general, Hispanics have been reported to have higher dietary quality and consume more dietary fibre than individuals from other ethnic backgrounds ${ }^{(3,7,17)}$.

Participants from both groups in the current study achieved the maximum score for total protein intake, as has been reported for the general US population ${ }^{(17,63)}$. However, poor scores were observed for the fatty acids category in both groups. The 2010 Dietary Guidelines for Americans $^{(32)}$ encourage replacing SFA with MUFA and PUFA to attain a ratio similar to that observed in the
Mediterranean diet. Such ratio requires a diet rich in vegetable oil, fish and nuts and low in animal fat ${ }^{(65,66)}$. In contrast, participants in the current study reported sources of fatty acids that included fatty meats, butter, mayonnaise and dairy (data not shown). NHANES data showed that Mexican Americans consumed diets with a higher content of saturated fat and cholesterol than other groups ${ }^{(3)}$. Hispanic women have reported dairy products and butter as the main source of saturated fat intake ${ }^{(67)}$.

\section{Moderation components of the Healthy Eating Index-2010}

Individuals in both groups in the current study had considerably high scores for refined grains, indicating a low consumption. According to the Multiethnic Cohort Study, which included participants aged 45-75 years, the major contributors of refined grains among Latinos are tortilla, bread, rolls, buns and biscuits ${ }^{(68)}$. Scores for sodium in the current study were low (less than $30 \%$ of the maximum score) for both groups, indicating high intake. Using nationally representative data, Cogswell et al. ${ }^{(69)}$ reported that about $86 \%$ of Mexican-American adults consumed $\mathrm{Na}$ over the recommended levels. Although women in both groups exceeded the maximum recommended $\mathrm{Na}$ intake of $2300 \mathrm{mg} / \mathrm{d}^{(32)}$ by only about $250-300 \mathrm{mg} / \mathrm{d}$, Na density of the diet was elevated, given the relatively low energy intake reported by both groups.

Despite low reported total energy intake, both groups had low scores for empty calories $56 \%$ of maximum score for older women and $47 \%$ of maximum score for younger women). This suggested mainly a high intake of solid fat and added sugars, as alcohol consumption was very low. The higher score for empty calories observed in the older women, relative to that of younger women, was in part attributed to a significantly lower intake of added sugars ( $11 \%$ and $17 \%$ of energy from added sugars in the older and younger women, respectively), as has been reported for the general US population ${ }^{(70)}$. Sharma et al. ${ }^{(67)}$ reported that regular soda and other fruit juices or drinks are the main contributor to sugar intake among Hispanic individuals. In the current study, sugar-sweetened beverages contributed $28 \%$ and $44 \%$ of all added sugars in older and younger women, respectively.

Fifty per cent of the older participants were born in the USA, while most (79\%) of the younger participants were born in Mexico $(P<0 \cdot 001)$. Although acculturation has been reported to influence dietary intake ${ }^{(12,15)}$, the current analysis was not adjusted for acculturation because of missing data. Nevertheless, the differences in acculturation between the two groups were based on language use, and not on the cultural dimensions more likely to affect diet. The subtle differences between the younger and older Mexican-American women may be related to residence time in the USA, as shown in research that related acculturation to diet intake and changes in food availability and intake following migration ${ }^{(71,72)}$. 


\section{Study limitations}

The present study has some limitations. The HEI-2010 evaluates conformance to the Dietary Guidelines for Americans $2010^{(32)}$, but is not necessarily predictive of health outcomes ${ }^{(31)}$ and may not appropriately reflect the needs and dietary patterns of cultural specific subgroups $^{(73)}$. Mean total energy intake was lower than what has been reported among US adult women (7544 (SD 59) $\mathrm{kJ} / \mathrm{d}$ (1803 (sD 14) kcal/d) according to NHANES 20092010 data $^{(74)}$ ), particularly considering that participants from the present study were overweight or obese, albeit sedentary. Food intake under-reporting is a major dietary assessment challenge that is highly prevalent, particularly among Hispanics, overweight and obese individuals, and women $^{(75,76)}$. This limitation was addressed by calculating the HEI-2010, which uses an energy-density approach to assess dietary quality independent of an individual's energy intake ${ }^{(33)}$. Moreover, to avoid overestimation of the proportion of the group at risk for nutrient inadequacy, EAR values (rather than RDA values) were used as cut-off points for nutrient requirements ${ }^{(30)}$. Nevertheless, given the general difficulty in meeting nutrient recommendations at energy levels below $6694 \mathrm{~kJ} / \mathrm{d}(1600 \mathrm{kcal} / \mathrm{d})$, there is a higher probability that these individuals have inadequate intake, even when achieving maximum HEI-2010 scores $^{(63,77)}$.

Finally, diet data included only one $24 \mathrm{~h}$ recall from the older women. Data from a single $24 \mathrm{~h}$ recall are not representative of participant's usual intake, as it does not account for within-person variation in daily intake. Although more than one recall would have been preferable, a single $24 \mathrm{~h}$ recall is considered a valid method for measuring nutrient intakes of groups ${ }^{(78)}$. While one dietary recall may be less precise and have a larger standard deviation than the average of three dietary recalls, the relatively large total sample ( $n$ 263) mitigates this loss of power.

\section{Conclusion}

In conclusion, the current study provides new information regarding dietary quality of older and younger MexicanAmerican women free of chronic disease. As the rate of obesity among this subset of the population continues to increase ${ }^{(79)}$, addressing inadequacies in food intake to help develop future interventions is of great importance. In addition, the current study used the recently updated HEI- $2010^{(33)}$ that measures the compliance to the Dietary Guidelines for Americans released in $2010^{(32)}$.

Despite differences in some of the individual HEI-2010 components, the overall HEI-2010 score suggests that both groups of Mexican-American women would benefit from dietary quality improvement. Overall, diet quality did not satisfy US dietary guidelines. Intervention strategies targeting Mexican-American women at these critical developmental periods are needed. Effective interventions could increase the awareness of Mexican-American women concerning which dietary patterns they are, by virtue of their age, likely to consume that may compromise their health, especially if they account for variations in diet quality as women transition through different stages of life to prevent diet-related chronic diseases. To address the issues identified herein, dietary interventions for women of childbearing age should emphasize fruit and vegetable intake, whereas interventions for older women should focus on whole grains and low-fat dairy. Regardless of age, nutrition interventions with Mexican-American women should address the replacement of SFA with MUFA and PUFA, and the selection of nutrient-dense foods, limiting solid fats, added sugars and sodium.

\section{Acknowledgements}

Acknowledgements: The authors thank Drs Cristina Barroso and Nancy Moore for reviewing this manuscript. Financial support: The data for this study were collected with support from the National Institutes of Health, National Institute of Nursing Research (NIH/NINR; grant number 1 R21 NR010126-01A1); Mujeres en Accion (Walking in Hispanic Women), NIH/NINR (grant number 1 R01 NR010356-01A2); and Madres para la Salud (Mothers for Health), NIH/NINR (grant number 3 R01 NR010356-02S1). Research assistance for data analysis and manuscript development was provided by training funds from the National Institute on Minority Health and Health Disparities of the National Institutes of Health (NIMHD/NIH; award number P20 MD002316). This material is the result of work supported in part by the Department of Veterans Affairs. The content is solely the responsibility of the authors and does not represent the views of the NIH, the Department of Veterans Affairs or the US Government. Conflict of interest: None. Authorship: G.A.P.P. and S.V.-L. contributed equally to the work presented in this manuscript. G.A.P.P. contributed with data collection, data analysis and manuscript preparation. S.V.-L. was involved in study design, data analysis and interpretation, and manuscript preparation. C.K. was involved in study design and manuscript preparation. M.B. was involved in conducting statistical analysis and assisted with data interpretation. A.N.W. contributed to data collection and manuscript preparation. B.A., K.R., D.C. and P.P. were involved in study design and manuscript preparation. Ethics of buman subject participation: This study was approved by the Institutional Review Board at Arizona State University.

\section{Supplementary material}

To view supplementary material for this article, please visit http://dx.doi.org/10.1017/S1368980014003085 


\section{References}

1. Pan L, Galuska DA, Sherry B et al.; Centers for Disease Control and Prevention (2009) Differences in prevalence of obesity among Black, White and Hispanic adults - United States, 2006-2008. MMWR Morb Mortal Wkly Rep 58, 740-744.

2. Daviglus ML, Talavera GA, Avilés-Santa ML et al. (2012) Prevalence of major cardiovascular risk factors and cardiovascular diseases among Hispanic/Latino individuals of diverse backgrounds in the United States. JAMA 308, 1775-1784.

3. Carrera PM, Gao X \& Tucker KL (2007) A study of dietary patterns in the Mexican-American population and their association with obesity. J Am Diet Assoc 107, 1735-1742.

4. Ervin RB \& Ogden CL (2013) Consumption of added sugars among US adults, 2005-2010. NCHS Data Brief issue 122, $1-8$.

5. Kirkpatrick SI, Dodd KW, Reedy J et al. (2012) Income and race/ethnicity are associated with adherence to food-based dietary guidance among US adults and children. J Acad Nutr Diet 112, 624-635.e6.

6. Ogden CL, Kit BK, Carroll MD et al. (2011) Consumption of sugar drinks in the United States, 2005-2008. NCHS Data Brief issue 71, 1-8.

7. Hoerr SL, Tsuei E, Liu Y et al. (2008) Diet quality varies by race/ethnicity of Head Start mothers. I Am Diet Assoc 108 651-659.

8. Keller C, Fleury J \& Rivera A (2007) Visual methods in the assessment of diet intake in Mexican American women. West J Nurs Res 29, 758-773.

9. Colby SE, Morrison S \& Haldeman L (2009) What changes when we move? A transnational exploration of dietary acculturation. Ecol Food Nutr 48, 327-343.

10. Zhang Q \& Wang Y (2012) Socioeconomic and racial/ethnic disparity in Americans' adherence to federal dietary recommendations. J Acad Nutr Diet 112, 614-616.

11. Dubowitz T, Heron M, Bird CE et al. (2008) Neighborhood socioeconomic status and fruit and vegetable intake among whites, blacks, and Mexican Americans in the United States. Am J Clin Nutr 87, 1883-1891.

12. Ayala GX, Baquero B \& Klinger S (2008) A systematic review of the relationship between acculturation and diet among Latinos in the United States: implications for future research. J Am Diet Assoc 108, 1330-1344.

13. Perez-Escamilla R (2009) Dietary quality among Latinos: is acculturation making us sick? J Am Diet Assoc 109, 988-991.

14. Duffey KJ, Gordon-Larsen P, Ayala GX et al. (2008) Birthplace is associated with more adverse dietary profiles for US-born than for foreign-born Latino adults. $J$ Nutr $\mathbf{1 3 8}$, 2428-2435.

15. Perez-Escamilla R (2011) Acculturation, nutrition, and health disparities in Latinos. Am J Clin Nutr $\mathbf{9 3}$, issue 5, 1163S-1167S.

16. Wakimoto P \& Block G (2001) Dietary intake, dietary patterns, and changes with age: an epidemiological perspective. J Gerontol A Biol Sci Med Sci 56, Suppl. 2, 65-80.

17. Hiza HA, Casavale KO, Guenther PM et al. (2013) Diet quality of Americans differs by age, sex, race/ethnicity, income, and education level. J Acad Nutr Diet $\mathbf{1 1 3}$, 297-306.

18. Keller C, Larkey L, Distefano JK et al. (2010) Perimenopausal obesity. J Womens Health (Larchmt) 19, 987-996.

19. Keller C, Fleury J, Perez A et al. (2011) Mujeres en Accion: design and baseline data. J Community Health 36, 703-714.

20. Keller CS, Records K, Ainsworth BE et al. (2011) Madres para la Salud: design of a theory-based intervention for postpartum Latinas. Contemp Clin Trials 32, 418-427.

21. Ainsworth BE, Keller C, Herrmann S et al. (2013) Physical activity and sedentary behaviors in postpartum Latinas: Madres para la Salud. Med Sci Sports Exerc 45, 1298-1306.

22. Fine A \& Kotelchuck M (2010) Rethinking MCH: The Life Course Model as an Organizing Framework (Version 1.1).
Rockville, MD: US Department of Health and Human Services.

23. Power ML \& Schulkin J (2008) Sex differences in fat storage, fat metabolism, and the health risks from obesity: possible evolutionary origins. Br J Nutr 99, 931-940.

24. Coe K (2003) The Ancestress Hypothesis: Visual Art as Adaptation. New Brunswick, NJ: Rutgers University Press.

25. Castro MJ (1997) Making pan-Latino. Latino pan-ethnicity and the controversial case of the Cubans. Harvard Latino Law Rev 2, 179-197.

26. Taylor-Piliae RE, Fair J, Haskell W et al. (2010) Validation of the Stanford Brief Activity Survey: examining psychological factors and physical activity levels in older adults. J Phys Act Health 7, 87-94.

27. Ainsworth BE, Haskell WL, Herrmann SD et al. (2011) Compendium of physical activities: a second update of codes and MET values. Med Sci Sports Exerc 43, 1575-1581.

28. Hazuda HP, Stern MP \& Haffner SM (1988) Acculturation and assimilation among Mexican Americans: scales and population-based data. Soc Sci $Q$ 69, 687-709.

29. Conway JM, Ingwersen LA \& Moshfegh AJ (2004) Accuracy of dietary recall using the USDA five-step multiple-pass method in men: an observational validation study. J Am Diet Assoc 104, 595-603.

30. Institute of Medicine (2001) Dietary Reference Intakes. Applications in Dietary Assessment. Washington, DC: National Academy Press.

31. Kant AK (2004) Dietary patterns and health outcomes. J Am Diet Assoc 104, 615-635.

32. US Department of Agriculture \& US Department of Health and Human Services (2010) Dietary Guidelines for Americans, 2010, 7th ed. Washington, DC: US Government Printing Office.

33. Guenther PM, Casavale KO, Reedy J et al. (2013) Update of the Healthy Eating Index: HEI-2010. J Acad Nutr Diet 113 , 569-580.

34. Freedman LS, Guenther PM, Krebs-Smith SM et al. (2008) A population's mean Healthy Eating Index-2005 scores are best estimated by the score of the population ratio when one 24-hour recall is available. J Nutr 138, 1725-1729.

35. US Department of Agriculture (1995) The Healthy Eating Index. Publication no. CNPP-1. Alexandria, VA: USDA Center for Nutrition Policy amd Promotion.

36. Miller PE, Mitchell DC, Harala PL et al. (2011) Development and evaluation of a method for calculating the Healthy Eating Index-2005 using the Nutrition Data System for Research. Public Health Nutr 14, 306-313.

37. Institute of Medicine (2005) Dietary Reference Intakes for Energy, Carbohydrate, Fiber, Fat, Fatty Acids, Cholesterol, Protein, and Amino Acids (Macronutrients). Washington, DC: The National Academies Press.

38. Institute of Medicine (2011) Dietary Reference Intakes for Calcium and Vitamin D [AC Ross, CL Taylor, AL Yaktine et al., editors]. Washington, DC: The National Academies Press.

39. Institute of Medicine (2001) Dietary Reference Intakes for Vitamin A, Vitamin K, Arsenic, Boron, Chromium, Copper, Iodine, Iron, Manganese, Molybdenum, Nickel, Silicon, Vanadium, and Zinc. Washington, DC: The National Academies Press.

40. Institute of Medicine (1998) Dietary Reference Intakes for Thiamin, Riboflavin, Niacin, Vitamin $B_{6}$, Folate, Vitamin $B_{12}$, Pantothenic Acid, Biotin, and Choline. Washington, DC: The National Academies Press.

41. Institute of Medicine (2000) Dietary Reference Intakes for Vitamin C, Vitamin E, Selenium, and Carotenoids. Washington, DC: The National Academies Press.

42. Greiner $\mathrm{T}$ (2011) Vitamins and minerals for women: recent programs and intervention trials. Nutr Res Pract $\mathbf{5}$, $3-10$. 
43. Bendich A (2001) Micronutrients in women's health and immune function. Nutrition 17, 858-867.

44. Perrig-Chiello P, Hutchison S \& Hoepflinger F (2008) Role involvement and well-being in middle-aged women. Women Health 48, 303-323.

45. Dubowitz T, Subramanian SV, Acevedo-Garcia D et al. (2008) Individual and neighborhood differences in diet among low-income foreign and US-born women. Womens Health Issues 18, 181-190.

46. McWilliams JM, Meara E, Zaslavsky AM et al. (2009) Differences in control of cardiovascular disease and diabetes by race, ethnicity, and education: US trends from 1999 to 2006 and effects of medicare coverage. Ann Intern Med 150, 505-515.

47. Guendelman S \& Abrams B (1995) Dietary intake among Mexican-American women: generational differences and a comparison with white non-Hispanic women. Am J Public Health 85, 20-25.

48. US Department of Agriculture (2013) Food Access Research Atlas. http://www.ers.usda.gov/data-products/food-accessresearch-atlas.aspx (accessed October 2014).

49. Moshfegh AJ, Goldman J \& Cleveland L (2005) What We Eat in America, NHANES 2001-2002: Usual Nutrient Intakes from Food Compared to Dietary Reference Intakes. Beltsville, MD: USDA, Agricultural Research Service.

50. Marriott BP, Olsho L, Hadden L et al. (2010) Intake of added sugars and selected nutrients in the United States, National Health and Nutrition Examination Survey (NHANES) 2003-2006. Crit Rev Food Sci Nutr 50, 228-258.

51. Colón-Ramos U, Thompson FE, Yaroch AL et al. (2009) Differences in fruit and vegetable intake among Hispanic subgroups in California: results from the 2005 California Health Interview Survey. J Am Diet Assoc 109, 1878-1885.

52. Stephens JW, Khanolkar MP \& Bain SC (2009) The biological relevance and measurement of plasma markers of oxidative stress in diabetes and cardiovascular disease. Atherosclerosis 202, 321-329.

53. Hamer M \& Chida Y (2007) Intake of fruit, vegetables, and antioxidants and risk of type 2 diabetes: systematic review and meta-analysis. J Hypertens 25, 2361-2369.

54. Lee JE, Giovannucci E, Smith-Warner SA et al. (2006) Intakes of fruits, vegetables, vitamins $\mathrm{A}, \mathrm{C}$, and $\mathrm{E}$, and carotenoids and risk of renal cell cancer. Cancer Epidemiol Biomarkers Prev 15, 2445-2452.

55. Scalbert A, Manach C, Morand C et al. (2005) Dietary polyphenols and the prevention of diseases. Crit Rev Food Sci Nutr 45, 287-306.

56. Gregory-Mercado KY, Staten LK, Gillespie C et al. (2007) Ethnicity and nutrient intake among Arizona WISEWOMAN participants. J Womens Health 16, 379-389.

57. Bazzano LA (2008) Effects of soluble dietary fiber on lowdensity lipoprotein cholesterol and coronary heart disease risk. Curr Atheroscler Rep 10, 473-477.

58. Pereira MA, O'Reilly E, Augustsson K et al. (2004) Dietary fiber and risk of coronary heart disease: a pooled analysis of cohort studies. Arch Intern Med 164, 370-376.

59. Looker AC, Borrud LG, Dawson-Hughes B et al. (2012) Osteoporosis or low bone mass at the femur neck or lumbar spine in older adults: United States, 2005-2008. NCHS Data Brief issue 93, 1-8.

60. Agopian AJ, Canfield MA, Olney RS et al. (2012) Spina bifida subtypes and sub-phenotypes by maternal race/ethnicity in the National Birth Defects Prevention Study. Am J Med Genet $A$ 158A, 109-115.
61. Aliyu MH, Salihu HM, Keith LG et al. (2005) Trends in birth across high-parity groups by race/ethnicity and maternal age. J Natl Med Assoc 97, 799-804.

62. Dixon LB, Sundquist J \& Winkleby M (2000) Differences in energy, nutrient, and food intakes in a US sample of Mexican-American women and men: findings from the Third National Health and Nutrition Examination Survey, 1988-1994. Am J Epidemiol 152, 548-557.

63. Guenther PM, Casavale KO, Kirkpatrick SI et al. (2013) Diet Quality of Americans in 2001-02 and 2007-08 as Measured by the Healthy Eating Index-2010. Nutrition Insight no. 51. Alexandria, VA: USDA Center for Nutrition Policy amd Promotion.

64. Beltsville Human Nutrition Research Center, Agricultural Research Service, US Department of Agriculture (2008) MyPyramid Equivalents Database, 2.0 for USDA Survey Foods, 2003-2004. http://www.ars.usda.gov/ba/bhnrc/fsrg (accessed August 2013).

65. Bergouignan A, Momken I, Schoeller DA et al. (2009) Metabolic fate of saturated and monounsaturated dietary fats: the Mediterranean diet revisited from epidemiological evidence to cellular mechanisms. Prog Lipid Res 48, 128-147.

66. Willett WC, Sacks F, Trichopoulou A et al. (1995) Mediterranean diet pyramid: a cultural model for healthy eating. Am J Clin Nutr 61, 6 Suppl., 1402S-1406S.

67. Sharma S, Wilkens LR, Shen L et al. (2013) Dietary sources of five nutrients in ethnic groups represented in the Multiethnic Cohort. Br J Nutr 109, 1479-1489.

68. Sharma S, Sheehy T \& Kolonel LN (2013) Ethnic differences in grains consumption and their contribution to intake of B-vitamins: results of the Multiethnic Cohort Study. Nutr J 12, 65.

69. Cogswell ME, Zhang Z, Carriquiry AL et al. (2012) Sodium and potassium intakes among US adults: NHANES 2003-2008. Am J Clin Nutr 96, 647-657.

70. Welsh JA, Sharma AJ, Grellinger L et al. (2011) Consumption of added sugars is decreasing in the United States. Am J Clin Nutr 94, 726-734.

71. Himmelgreen D, Romero Daza N, Cooper E et al. (2007) 'I don't make the soups anymore': pre- to post-migration dietary and lifestyle chanes among Latinos living in WestCentral Florida. Ecol Food Nutr 46, 427-444.

72. Guarnaccia PJ, Vivar T, Bellows AC et al. (2012) 'We eat meat every day': ecology and economy of dietary change among Oaxacan migrants form Mexico to New Jersey. Ethnic Racial Stud 35, 104-119.

73. Tucker KL (2010) Dietary patterns, approaches, and multicultural perspective. Applied Physiol Nutr Metab 35, 211-218.

74. Ford ES \& Dietz WH (2013) Trends in energy intake among adults in the United States: findings from NHANES. Am J Clin Nutr 97, 848-853.

75. Neuhouser ML, Tinker L, Shaw PA et al. (2008) Use of recovery biomarkers to calibrate nutrient consumption selfreports in the Women's Health Initiative. Am J Epidemiol 167, 1247-1259.

76. Bothwell EKG, Ayala GX, Conway TL et al. (2009) Underreporting of food intake among Mexican/Mexican-American women: rates and correlates. J Am Diet Assoc 109, 624-632.

77. Britten P, Cleveland LE, Koegel KL et al. (2012) Updated US Department of Agriculture Food Patterns meet goals of the 2010 dietary guidelines. J Acad Nutr Diet 112, 1648-1655.

78. Thompson FE \& Byers T (1994) Dietary assessment resource manual. J Nutr 124, 11 Suppl., 2245S-2317SS.

79. Flegal KM, Carroll MD, Ogden CL et al. (2010) Prevalence and trends in obesity among US adults, 1999-2008. JAMA 303, 235-2341. 